\title{
REVIEW
}

\section{Safety and Tolerability of Fesoterodine in Older Adult Patients with Overactive Bladder}

\author{
John Heesakkers, MD, $\mathrm{PhD}^{1,2}$, Manon te Dorsthorst, $\mathrm{MD}^{1}$, Adrian Wagg, MBBS, $\mathrm{FRCP}^{3}$ \\ ${ }^{1}$ Department of Urology, Radboud University Medical Center, Nijmegen, The Netherlands; ${ }^{2}$ Department \\ of Urology, Maastricht University Medical Center, Maastricht, The Netherlands; ${ }^{3}$ Department of Medicine, \\ University of Alberta, Edmonton, Alberta, Canada
}

https://doi.org/10.5770/cgj.25.530

\begin{abstract}
\section{Background}

Older patients ( $>65 \mathrm{yr}$ ) suffering from overactive bladder $(\mathrm{OAB})$ are more likely to have functional impairment and comorbidity than those without $\mathrm{OAB}$. This article reviews available published studies and discusses how fesoterodine might meet the specific needs of the older OAB patient.
\end{abstract}

\section{Methods}

A comprehensive literature search was undertaken in order to evaluate fesoterodine safety in older OAB patients.

\section{Results}

Fesoterodine offers flexible dosing, allowing the clinician to balance risk and benefits according to the symptoms and preferences of the patient. Its balanced affinity for M2 and M3 muscarinic receptors may lead to its benefit on OAB symptoms. Its active metabolite is a P-gp substrate that is actively transported from the central nervous system (CNS), potentially avoiding adverse CNS effects. Fesoterodine can be used in mild or moderate hepatic or renal insufficiency and no dose adjustment is routinely required. Fesoterodine's benefit has been demonstrated in multiple clinical trials in older and medically vulnerable patients. Fesoterodine was rated as "beneficial" in the LUTS-FORTA classification due to its efficiency and tolerability in older patients.

\section{Conclusion}

Here, the use of fesoterodine in older and vulnerable patients is summarized given the need to approach pharmacotherapy for OAB differently in older adults.

Key words: fesoterodine, tolerability, older patients, vulnerable patient, LUTS-FORTA

\section{INTRODUCTION}

Overactive bladder $(\mathrm{OAB})$ is characterized by urinary urgency that may be associated with urinary frequency, urgency urinary incontinence (UUI), and nocturia. ${ }^{(1)} \mathrm{OAB}$ is twice as common in adults over 65 years of age than in those aged 45 years or younger. ${ }^{(2,3)}$ Older patients, conventionally defined as being 65 years and older, ${ }^{(4)}$ suffering from OAB have higher levels of functional impairment and physical limitations, comorbidity, and concomitant medication use than in those patients over 65 years of age without OAB. ${ }^{(5)}$ Patients with $\mathrm{OAB}$ are more likely to be frail than individuals seeking care for other nononcologic urologic diagnoses. Interestingly, when adjusted for frailty, age is not significantly associated with a diagnosis of $\mathrm{OAB}$, suggesting that the association of frailty with $\mathrm{OAB}$ may be more meaningful than age alone. ${ }^{(6)} \mathrm{OAB}$ represents a considerable burden as a result of the distress and disruption to daily life, with a negative impact on quality of life (QoL). (7) $\mathrm{OAB}$ also represents a growing economic burden. ${ }^{(4)} \mathrm{Un}$ fortunately, $\mathrm{OAB}$ in older people remains underdiagnosed and undertreated. ${ }^{(7-9)}$

In older patients, management of $\mathrm{OAB}$ requires a specific approach that integrates all identified contributory factors. The Fit fOR The Aged (FORTA) classification applied to lower urinary tract symptoms (LUTS) (LUTS-FORTA) analyzed the appropriateness of oral OAB drugs in older patients (defined as those $>65$ with two or more comorbid conditions) and ranked these medications based on published studies. ${ }^{(10)}$ Of all of the available OAB drugs, fesoterodine was ranked as beneficial, while other $\mathrm{OAB}$ medications were rated as a $\mathrm{C}$ (Caution) or D (Don't prescribe). This ranking was made on the basis of the published evidence from fesoterodine studies in patients over 65 years.

This article first discusses the prevalence and impact of $\mathrm{OAB}$ in older people and the characteristics of fesoterodine which might lend itself to meeting the needs of older adults, 
and reviews applicable data on the use of fesoterodine in clinical trials in older adults and those with medical complexity.

This article is based on a comprehensive Medline literature search. Articles were identified using the search terms: fesoterodine, overactive bladder, older adult patients, safety. The authors reviewed the published studies and analyzed the scientific background demonstrating how fesoterodine might accommodate the specific needs of the older OAB patient.

\section{OLDER PATIENTS WITH OAB: WHO ARE THEY?}

\section{OAB is Common in Older People}

The prevalence of OAB increases with age. ${ }^{(11)}$ In a populationbased survey including six European countries (France, Germany, Italy, Spain, Sweden, UK), the prevalence of OAB was found to increase with age in women, being $17.5 \%$ at $65-69$ years, $22.1 \%$ at $70-74$ years, to $31.3 \%$ at 75 years or older; while in men these figures were $23.7 \%, 22.3 \%$, and $41.9 \%$, respectively. ${ }^{(12)}$ The prevalence of incontinence ranged between $52.2 \%$ and $65.2 \%$ in nursing home residents in five European countries and was $42.9 \%$ in Japan and $46.4 \%$ in USA. ${ }^{(13)}$ A population-based study of more than 19,000 individuals in Canada and Europe estimated the prevalence of OAB as close to $20 \%$ for subjects aged 60 years or over. ${ }^{(14)}$

\section{Older People Are Not a Homogeneous Group}

Older adults range from the physically robust to the multimorbid, vulnerable or frail. With aging and the emergence of comorbidities, there is decreased absorption and an altered distribution of drugs; medications may also require dose adjustments due to impaired hepatic and renal function. ${ }^{(4)}$ Frail older persons - defined as those over the age of 65 with a clinical presentation including impaired functioning in physical activity, mobility, balance, muscle strength, motor processing, cognition, nutrition, and endurance - commonly suffer multiple medical conditions, take several medications, and have an increased risk of drug-drug interactions, require care and present a higher risk of disability, hospitalization, and death. ${ }^{(4)}$ Adverse drug events are more common in the frail older patients. ${ }^{(4)}$ However, patients living with frailty may receive comparable benefit and have similar rates of side effects compared to less frail older individuals. ${ }^{(15)}$ Similarly, vulnerable older adults, who may or may not be frail, are defined as those with increased risk of notable functional decline or death in the near future. ${ }^{(3,16)}$

\section{WHAT IS DIFFERENT ABOUT THE APPROACH NEEDED TO EFFECTIVELY TREAT OAB IN OLDER PEOPLE?}

OAB patients often modify their behaviour and develop strategies to reduce the impact of their symptoms. This may have an associated deleterious effect; limiting fluid intake can lead to dehydration, impair renal function contributes to orthostatic hypotension and constipation, while limiting social and physical activities can be detrimental to psychological and physical well-being. ${ }^{(17)}$ A self-reported internet survey of older adults with OAB symptoms showed that diagnosed older respondents had higher mental component summary (MCS) scores (in favour of better QoL), higher SF-6D health utilities (in favour of better health status), and less activity impairment than those undiagnosed. ${ }^{(7)}$ Treated versus never treated older respondents had higher MCS and SF-6D health utilities, less activity impairment, fewer OAB symptoms, less $\mathrm{OAB}$ symptom bother, and lower odds of having bladder problems or incontinence. OAB treatment may, therefore, help decrease its associated burden.

Besides the discomfort of symptoms, OAB patients experience greater levels of depression, anxiety, and shame; difficulties with their social life; impact on sleep and sexual relationships; and a lower QoL than people without OAB. (18) Moreover, some consequences of OAB can be lifethreatening; urinary urgency, frequency, incontinence, and nocturia have been identified as risk factors for falls with a higher mortality and a worsened prognosis after stroke. ${ }^{(4)}$ Indeed, the increased risk of falls is well-documented. $(19,20)$ In older women with UUI, the risk of falls was increased by $26 \%$ and the risk of fractures by $34 \% .^{(21)}$ Szabo et al. ${ }^{(22)}$ reported a significantly increased (1.3- to 2.3-fold) adjusted OAB-associated risk of falls, with $18.9 \%$ to $50.0 \%$ of patients experiencing at least one fall over a year.

OAB patients are underdiagnosed and undertreated. In a Spanish population of patients aged 60 years or over, $50 \%$ considered their OAB symptoms normal for their age/sex, which could explain the considerable delays before seeking health care. ${ }^{(9)}$ In the US cohort of the population-based EpiLUTS study, $40 \%$ of men and $47 \%$ of women aged 65 years or older had symptoms of OAB. Among patients with symptoms, fewer than $40 \%$ of men and $25 \%$ of women had sought treatment, and only $27.2 \%$ of men and $13.6 \%$ of women had received medication. ${ }^{(8)}$ The belief that incontinence is normal for getting older, and a lack of awareness that incontinence is a treatable condition, may prevent access to diagnosis and treatment. ${ }^{(4-23)}$

The economic impact of OAB is growing with the increasing older population. Excess annual direct costs associated with the diagnosis, treatment, medical consultations, and treatment of depression associated with OAB have been estimated at between $255 €$ to $584 €$ per patient, depending on the European country included in the EPIC study. ${ }^{(24)}$ The cost of care for older persons has been estimated at double that for people under the age of 65 years. ${ }^{(4)}$

In clinical practice, managing older patients with $\mathrm{OAB}$ symptoms can be complicated by multiple chronic comorbidities, concomitant medications, and functional or cognitive impairment. ${ }^{(4)}$ Likewise, the pharmacological treatment of older patients may be of particular concern for clinicians due to possible treatment-related adverse events (AEs) including constipation, falls, cognitive decline, or urinary retention. ${ }^{(25)}$ $\mathrm{OAB}$ treatment should be chosen on an individual basis, taking into account the patient's expectations, tolerability, absence 


\section{HEESAKKERS: SAFETY OF FESOTERODINE IN OLDER OAB PATIENTS}

of drug interactions, and cognitive safety. ${ }^{(11)}$ At treatment initiation, it is important to agree to realistic goals with the patient and encourage them to continue their treatment in order to achieve them.

The current European Association of Urology (EAU) guidelines for the treatment of LUTS and urinary incontinence state that "long-term antimuscarinic treatment should be used with caution in older patients especially those who are at risk of, or have, cognitive dysfunction". However, EAU guidelines also admit that not all antimuscarinics have a similar impact on cognitive function. ${ }^{(26)}$ Therefore, the choice of drug should be based on its characteristics, and should correspond to the specific requirements of older patients whilst having evidence of clinical benefit.

\section{PHARMACOLOGICAL PROPERTIES OF FESOTERODINE}

Fesoterodine possesses four pharmacological properties that make it potentially suitable for older adults: 1) The active metabolite of fesoterodine, 5-hydroxymethyl tolterodine (5HMT), has limited ability to cross the blood-brain barrier, and is a P-glycoprotein (P-gp) substrate, actively transported from the CNS; 2) Fesoterodine does not undergo first-pass hepatic activation; 3) It is a prolonged release drug; and 4) It has a balanced affinity for M2 and M3 receptors. These factors are discussed in detail below. ${ }^{(11)}$ The pharmacokinetic properties of fesoterodine appear particularly beneficial for older patients. ${ }^{(27,28)}$ It is a prodrug, with rapid and extensive formation of 5-HMT, which does not undergo first-pass hepatic activation, but is metabolized by non-specific ubiquitous peripheral esterases that are not dependent on the individual's enzymatic makeup and are not affected by age. This simple metabolism may explain the consistency of response to fesoterodine across patients. ${ }^{(11,29)}$ The active metabolite of fesoterodine does not inhibit or induce cytochrome P450 enzymes. Patients with hepatic dysfunction have altered cytochrome P450 metabolism and, as this enzyme is needed for clearance of oxybutynin, tolterodine, darifenacin, and solifenacin, ${ }^{(30)}$ fesoterodine is more suitable in these patients. Dose adjustment is not necessary in patients with mild or moderate hepatic dysfunction, or in patients with mild or moderate renal impairment; however, fesoterodine is contraindicated in case of severe hepatic impairment or severe renal impairment associated with the presence of potent CYP3A4 inhibitors. ${ }^{(30)}$ In comparison, reduced renal function should be considered with renally excreted drugs such as trospium and tolterodine. ${ }^{(30)}$

No dose adjustment of fesoterodine is needed in older patients, and food has no clinically relevant effect on the pharmacokinetics of this drug. The prolonged release formulation permits once-daily dosing for both the $4 \mathrm{mg}$ and $8 \mathrm{mg}$ doses, which allows flexible dosage and facilitates adherence. ${ }^{(28)}$

5-HMT, the active metabolite of fesoterodine, has a high molecular weight and the lowest lipophilicity (0.74) of the antimuscarinics, except for trospium, which is a quaternary amine. ${ }^{(31)}$ Moreover, 5-HMT is actively transported from the brain by the P-gp, an efflux transporter system. ${ }^{(27,28,31,32)} \mathrm{An}$ timuscarinics that are substrates of the P-gp efflux transporter, such as 5-HMT, darifenacin, and trospium, have been shown to exhibit lower levels of brain penetration than agents that are not P-gp substrates, such as oxybutynin, solifenacin, and tolterodine. As a result, fesoterodine presents a profile that may lead to a low likelihood of CNS AEs, as confirmed in clinical trials in older patients. ${ }^{(16,33,34)}$

Fesoterodine has a balanced affinity for M2 and M3 receptors, whereas solifenacin and darifenacin have a relative affinity for M3.(29) All muscarinic receptor subtypes have been detected in the human bladder; however, the M2 and M3 receptors seem to be the most important in the regulation of the complex process of bladder function. As a result of its balanced M2-M3 affinity, fesoterodine has an effect on the control of contraction (M3), may have an effect on relaxation (M2), and also acts via the efferent sensory arm (M2)..$^{(11,29,35)}$

\section{CLINICAL STUDIES OF FESOTERODINE IN OLDER PATIENTS}

\section{Efficacy and Safety in Older Patients}

Several studies have evaluated the efficacy and safety of fesoterodine in older OAB patients. In the Study Of Fesoterodine In the Aged (SOFIA) study, a 12-week European randomized controlled trial involving 794 participants with OAB (men and women aged $\geq 65$ years, with purposeful recruitment of $30 \%$ of participants $>75$ years of age), patients were randomized 1:1 to fesoterodine or placebo. ${ }^{(33)}$ SOFIA used a flexible dosing approach to reflect clinical practice, and at Week 4, 52\% of patients treated with fesoterodine chose to increase their dose from $4 \mathrm{mg}$ to $8 \mathrm{mg}$, with a further $16 \%$ choosing to do so at Week 8 , while $4 \%$ reduced their dose during the study. At Week 12, there was a statistically significantly greater improvement from baseline in urgency episodes, severe urgency episodes $(-1.55$ vs. $-2.40, p<.001)$, and incontinence pad use with fesoterodine flexible dosing versus placebo, as well as an improvement in QoL and a reduction in symptom bother scores. Improvements in disease-related and patient-reported outcomes were observed in both age groups $(\leq 75$ and $>75$ years), with similar rates of AEs and discontinuations across all ages. The most common AEs during double-blind treatment were dry mouth (fesoterodine $34 \%$, placebo $5 \%$; predominantly mild in both groups) and constipation (fesoterodine 9\%, placebo 3\%). No change in mean Mini-Mental State Examination (MMSE) score was observed from baseline to Week 12 in either treatment group, with mean MMSE scores at Week 12 of 28.4 (range 20-30) in the fesoterodine group and 28.3 (range 19-30) in the placebo group. No clinically relevant changes from baseline were observed in vital sign measurements in either group. Discontinuation rates due to AEs were $12 \%$ for fesoterodine and $6 \%$ for placebo. The most common AE leading to discontinuation was dry mouth, with a low $(3 \%)$ rate of severe dry mouth.

Most of the patients who completed the SOFIA study continued in an open-label study for a further 12 weeks. ${ }^{(36)}$ 
Patients taking fesoterodine during double-blind treatment maintained their dose, whereas patients taking placebo started on fesoterodine $4 \mathrm{mg}$ with the option to increase to $8 \mathrm{mg}$ at Weeks 16 or 20. Improvements in OAB symptoms and QoL measures were maintained for patients who had previously received fesoterodine. At the end of the open-label study, efficacy outcomes in patients who received placebo during the double-blind phase were similar to those who had received fesoterodine, with noticeable improvements in OAB-q Symptom Bother, total health-related quality of life (HRQL) scores, and all HRQL domain scores during the open-label phase. Mean changes from the double-blind baseline in diary variables were similar at Week 24 and in patients aged $\leq 75$ and $>75$ years. Flexible dose fesoterodine was generally well tolerated in both age groups. Few patients who had received fesoterodine during the double-blind phase reported dry mouth and constipation during the open-label phase of the trial: $7 \%$ and $2 \%$, respectively, versus $28 \%$ and $6 \%$ in the group that had received placebo in the double-blind phase, and these patients also reported a lower discontinuation rate due to AEs ( $4 \%$ vs. $10 \%$ ). Patients treated for a longer time tended to report fewer AEs.

A post hoc analysis ${ }^{(37)}$ of data from the 12 -week, doubleblind phase of the SOFIA study investigated factors associated with dose escalation. At baseline, body mass index and male sex were significantly associated with an increased likelihood of dose escalation at Week 4; while Week 4 changes from baseline in urgency episodes and a worse patient perception of bladder control score were also associated with dose escalation.

An additional pooled post hoc analysis ${ }^{(38)}$ evaluated the efficacy and safety of fesoterodine according to age, using data from two randomized, double-blind, placebo-controlled, 12week studies where the patients with $\mathrm{OAB}$ were randomized to fesoterodine or placebo. ${ }^{(39,40)}$ The data were categorized into three age groups: from those $<65$ years, $65-74$ years, and $\geq 75$ years. The results demonstrated a significant decrease versus placebo in UUI episodes per 24 hours in the three groups in patients treated with fesoterodine at $8 \mathrm{mg}$. At Week 12, treatment response rates (patient condition rated as "improved" or "greatly improved" on the validated four-category Treatment Benefit Scale) were significantly higher with fesoterodine 4 $\mathrm{mg}$ and $8 \mathrm{mg}$ versus placebo in all three age groups, with a dose-dependent effect. At Week 12, fesoterodine $4 \mathrm{mg}$ and 8 $\mathrm{mg}$ significantly improved all bladder diary endpoints (number of micturitions, urgency episodes, UUI per 24 hours, and the mean voided volume (MVV) per micturition) versus placebo $(p<.05)$ in patients aged $\leq 65$ years. For those aged $65-74$ years, fesoterodine 4 and $8 \mathrm{mg}$ significantly improved all diary variables, except for MVV and micturition frequency. In subjects aged $\geq 75$ years, fesoterodine $8 \mathrm{mg}$ significantly improved all diary variables, except for MVV. Fesoterodine treatment was generally well tolerated. The rate of dry mouth with fesoterodine $8 \mathrm{mg}$ was greater in the subjects aged $\geq 75$ years $(9.3 \%)$ than in those aged $<65(6.6 \%)$ or $65-74$ years (8.3\%). However, most cases of dry mouth and constipation were rated by patients as mild or moderate, and the rate of discontinuation associated with these AEs did not increase in association with age. The rates of dry mouth and constipation were generally higher with fesoterodine $8 \mathrm{mg}$ than with fesoterodine $4 \mathrm{mg}$ or placebo in all age groups, confirming fesoterodine's role as an effective and well-tolerated treatment for $\mathrm{OAB}$ in older patients.

The long-term safety and efficacy of fesoterodine was assessed in a post hoc analysis of two open-label, long-term (up to 36 months), flexible dose (initiated with $8 \mathrm{mg}$ with a possible de-escalation) extension trials, ${ }^{(39,40)}$ with patient stratification by age: $<45,45-64,65-74$, and $\geq 75$ years. ${ }^{(41)} \mathrm{Pa}$ tients received fesoterodine for a mean duration of 20 months. Improvements in $\mathrm{OAB}$ symptoms and patient-reported $\mathrm{HRQL}$ outcomes were maintained in all age groups. In the overall safety population, $51 \%$ of patients had discontinued treatment at 24 months and $56 \%$ at 28 months. Approximately $80 \%$ of continuing subjects were receiving the 8-mg dose of fesoterodine at each visit after open-label baseline for up to 36 months. Throughout treatment, $77 \%$ percent of subjects taking $8 \mathrm{mg}$ as an initial dose elected to remain on fesoterodine $8 \mathrm{mg}$ for the duration of the open-label phase; this rate was highest (87\%) among subjects aged $\geq 75$ years. The significant improvements in all diary variables - including UUI episodes per 24 hours, micturitions per 24 hours, urgency episodes per 24 hours, and MVV per micturition - observed between double-blind baseline and open-label baseline were sustained or increased during open-label treatment in the overall population and all age groups. No new or unexpected safety signals were observed in any age group. Most subjects reported "good" or "excellent" treatment tolerance throughout the study $(\geq 75$ years, $\geq 86 \%$ ). Dry mouth, the most commonly reported treatment-emergent $\mathrm{AE}$, was lowest among subjects aged $\geq 75$ years ( $26 \%$ vs. $30-32 \%$ for the other age groups). Rates of discontinuation due to dry mouth were low $(1-3 \%)$ in all age groups. The incidence of treatment-related AEs increased numerically with age, but was similar across age groups.

These data suggest that fesoterodine treatment is generally well tolerated and effective across a wide age range and for a long period, and provides strong evidence for the safety, tolerability, and efficacy of long-term fesoterodine 8 $\mathrm{mg}$ treatment across multiple age groups. These findings also support the clinical use of high-dose fesoterodine as part of a flexible dose regimen for the management of OAB symptoms in adult subjects of all ages. Fesoterodine's benefit/safety ratio has recently been examined using the Multicriterion Decision Analysis (MCDA) model for comparing the benefits and risks of OAB medical treatments. Fesoterodine dosed flexibly ( 4 or $8 \mathrm{mg}$ ) was found to have the most favourable benefit-safety profile compared to other available $\mathrm{OAB}$ pharmacological treatments. ${ }^{(42)}$

\section{Tolerability in Vulnerable Patients}

The effect of fesoterodine has been assessed in "medically complex" vulnerable older people with UUI, identified at baseline by having a score of 3 or more on the Vulnerable 


\section{HEESAKKERS: SAFETY OF FESOTERODINE IN OLDER OAB PATIENTS}

Elders Survey (VES-13). ${ }^{(16)}$ A score of $\geq 3$ is associated with 4.2 times the risk of death or functional decline over a two-year period compared with those with scores $<3$. ${ }^{(43)}$ All included patients had an MMSE score $\geq 20{ }^{(16)}$ In this flexible dose, 12-week trial, patients were randomized 1:1 to receive fesoterodine or placebo. The study included 562 patients with a mean (range) age of 75 (65-91) years, a mean (range) of 8.5 (1-27) comorbid conditions, and a mean (range) of 8.5 (1-40) concomitant medications. At Week 12 the fesoterodine group had statistically significantly greater improvements in UUI episodes per 24 hours (-2.84 vs. $-2.20, p=.002)$ and most other diary variables. Patients receiving fesoterodine were more likely to report improvement on the Patient Perception of Bladder Condition (PPBC) at Weeks 4 and $12(p=.002)$. Fesoterodine also resulted in a statistically significantly greater improvement in scores on the OAB-q Symptom Bother $(p<.001)$ and HRQL $(p=.003)$ scales versus placebo. By Week 12, patients receiving fesoterodine, versus placebo, also reported significantly higher scores in $\mathrm{OAB}$ symptom bother (placebo: -20.1 [1.6], fesoterodine: -28.1 [1.6], $p<$ $.005)$, the OAB Satisfaction Questionnaire: Satisfaction with OAB Control Module (OAB-S:C) $(p<.001)$, and the Global Medication Satisfaction question (OAB-S:GMS) $(p<.001)$. Additionally, there were statistically significantly superior reductions in pad use, (for those using $\leq 3.5$ products $/ 24 \mathrm{~h}$ at baseline, the change from baseline was -0.27 [placebo] and -0.61 [fesoterodine] $[p<.004])$. In terms of safety, serious AEs occurred in eight (2.8\%) subjects receiving fesoterodine and six $(2.1 \%)$ receiving placebo. None was considered treatment-related by the investigator. Fesoterodine treatment was generally well tolerated; dry mouth (fesoterodine, $24 \%$; placebo, 6\%) and constipation (fesoterodine, 11\%; placebo, $4 \%$ ) were the most common AEs, which were mild to moderate in most patients. There was no change in mean MMSE scores for subjects in either treatment group.

\section{Effect on Cognitive Function}

The effect of fesoterodine on cognitive function has been evaluated in a double-blind, placebo and active controlled crossover study, where 20 healthy older individuals aged from 65 to 85 years with a score $\geq 26$ on the MMSE at baseline received (over four different periods) fesoterodine $4 \mathrm{mg}$ for six days; fesoterodine $4 \mathrm{mg}$ for three days, then fesoterodine $8 \mathrm{mg}$ for three days; placebo for six days; or placebo for six days with alprazolam $1 \mathrm{mg}$ on Day 6 as an active control, with a three- to six-day washout period between treatments. ${ }^{(34)} \mathrm{A}$ battery of cognitive tests, with a detection task as the primary endpoint and a range of tests assessing different cognitive domains were performed on Days 1 and 6 of each period. Alprazolam induced sedation and a large, statistically significant deterioration in cognitive functioning versus placebo. In contrast, fesoterodine, $4 \mathrm{mg}$ and $8 \mathrm{mg}$, showed no statistically significant effects on any of the domains assessed, including memory, compared to placebo. ${ }^{(34)}$ In a pooled analysis of 10 fesoterodine trials examining efficacy and safety information from older patients, the number of CNS AEs was low and the number of observed CNS-related AEs was not associated with fesoterodine dose. Moreover, there was no consistent effect of age on the likelihood of a CNS-related AE being reported. ${ }^{(44)}$ A limitation of both these cognitive function studies and the prospective clinical trials in older adult patients is that there are no data from use in the cognitively impaired. Caution should be exercised when using an antimuscarinic agent for $\mathrm{OAB}$ in an older patient with cognitive impairment.

The 2019 EAU guidelines ${ }^{(26)}$ dedicate a specific chapter to older adults and cognition which concludes that antimuscarinic drugs and mirabegron are effective in older patients. Oxybutynin may worsen cognitive function. Solifenacin, darifenacin, fesoterodine, and trospium have been shown not to cause cognitive dysfunction in short-term studies.

Cognition was also assessed in a recently published randomized, double-blind, placebo-controlled four-week study with a four-week, open-label extension phase in 63 Parkinson's disease patients with OAB symptoms who were mostly older adults (mean age over 65 years). ${ }^{(45)}$ The number of micturition episodes per 24 hours significantly improved with fesoterodine in the double-blind phase $(p<.001)$, and the mean number of nocturia and urgency episodes also decreased. There was an improvement of the mean number of micturition, urgency, and UUI episodes in the open-label phase. Cognitive function, as assessed by MMSE score, was stable after four weeks of fesoterodine $4 \mathrm{mg}$ treatment. The tolerability of fesoterodine in older adults with Parkinson's disease was not worse than in older subjects without this condition.

\section{Treatment Adherence}

Adherence to treatment is a key factor in ensuring the efficacy of OAB treatments. Evidence suggests that overall, adherence is poor in community-dwelling adults, but older people appear to be more likely than younger people to persist with treatment; the reasons why are as yet under-investigated. In a cohort of patients aged $\geq 66$ years old, Vouri et al. ${ }^{(46)}$ showed that among 42,886 new users of eight different antimuscarinics, fesoterodine was associated with the lowest percentage of patients discontinuing therapy (64.5\%) within a year following antimuscarinic initiation.

\section{Costs}

A cost-analysis study evaluating the treatment costs of vulnerable OAB patients $(\geq 65$ years with a VES score $\geq 3$ and risk of deteriorating health) including fesoterodine costs, health-care resources, and OAB-related comorbidities (falls/fractures, urinary tract infections, depression, and nursing home costs) found that fesoterodine was cost-saving compared to no OAB pharmacotherapy, and could save US $\$ 1,616$ per patient per year. Fesoterodine accounted for only $4 \%$ of the total medical costs in vulnerable older patients. ${ }^{(47)}$

\section{CONCLUSION}

Fesoterodine has demonstrated efficacy in patients $\geq 65$ years of age with both OAB-dry and OAB-wet. These data 
contribute to the "beneficial" rating given to fesoterodine in the LUTS-FORTA classification. The tolerability in these medically complex, vulnerable patients may be extendable to all $\mathrm{OAB}$ patients, offering the benefits of flexible dosing, thereby permitting individual balancing of the risk-benefit ratio, according to patient preference.

\section{ACKNOWLEDGEMENTS}

Not applicable.

\section{CONFLICT OF INTEREST DISCLOSURES}

We have read and understood the Canadian Geriatrics Journal's policy on conflicts of interest disclosure. J. Heesakkers has received support as a consultant/lecturer from Astellas, Allergan, Bluewind, UrogynBV, and Pierre Fabre, and for scientific studies and trials from Astellas, Boston Scientific, Ipsen, Bluewind, and UrogynBV. M. te Dorsthorst has received an unrestricted grant from Bluewind. A. Wagg has received honoraria from Astellas as a speaker and for consulting; from Essity Health \& Hygiene AB for consulting, research and as a speaker; from Pfizer Corporation for consulting and research grants; and honoraria from Pierre Fabre as a speaker.

\section{FUNDING}

Pierre Fabre Laboratories sponsored the writing assistance (by Azimut, Castres, France).

\section{REFERENCES}

1. D'Ancona C, Haylen B, Oelke M, et al. Standardisation Steering Committee ICS and the ICS Working Group on Terminology for Male Lower Urinary Tract and Pelvic Floor Symptoms and Dysfunction. The International Continence Society (ICS) report on the terminology for adult male lower urinary tract and pelvic floor symptoms and dysfunction. Neurourol Urodyn. 2019;38(2):433-77.

2. Stewart WF, Van Rooyen JB, Cundiff GW, et al. Prevalence and burden of overactive bladder in the United States. World $J$ Urol. 2003;20(6):327-36.

3. Wolff GF, Kuchel GA, Smith PP. Overactive bladder in the vulnerable elderly. Res Rep Urol. 2014;6:131-38.

4. Wagg AS, Chen LK, Johnson T, et al. Incontinence in the frail elderly. In: Abrams P, Cardozo L, Wagg A, Wein A, eds. Incontinence, 6th ed. Bristol, UK: International Continence Society; 2017.

5. Ganz ML, Liu J, Zou KH, Bhagnani T. Real-world characteristics of elderly patients with overactive bladder in the United States. Curr Med Res Opin. 2016;32(12):1997-2005.

6. Suskind AM, Quanstrom K, Zhao S, et al. Overactive bladder is strongly associated with frailty in older individuals. Urology. 2017;106:26-31.

7. Lee LK, Goren A, Zou KH, et al. Potential benefits of diagnosis and treatment on health outcomes among elderly people with symptoms of overactive bladder. Int J Clin Pract. 2016;70(1):66-81.
8. Sexton C, Coyne K, Thompson C, Bavendam T, Chen CI, Markland A. Prevalence and effect on health-related quality of life of overactive bladder in older Americans: results from the epidemiology of lower urinary tract symptoms study. $J \mathrm{Am}$ Geriatr Soc. 2011;59(8):1465-70.

9. Blasco P, Valdivia MI, Oña MR, Roset M, Mora AM, Hernández M . Clinical characteristics, beliefs, and coping strategies among older patients with overactive bladder. Neurourol Urodyn. 2017;36(3):774-79.

10. Oelke M, Becher K, Castro-Diaz D, et al. Appropriateness of oral drugs for long-term treatment of lower urinary tract symptoms in older persons: results of a systematic literature review and international consensus validation process (LUTS-FORTA 2014). Age Ageing. 2015;44(5):745-55.

11. Heesakkers J, Pons ME, Hobson PT, Chartier-Kastler E. Dealing with complex overactive bladder syndrome patient profiles with focus on fesoterodine: in or out of the EAU guidelines? Res Rep Urol. 2017;9:209-18.

12. Milsom I, Abrams P, Cardozo L, Roberts RG, Thüroff J, Wein AJ. How widespread are the symptoms of an overactive bladder and how are they managed? A population-based prevalence study. BJU Int. 2001;87(9):760-66.

13. Sgadari A, Topinková E, Bjørnson J, Bernabei R. Urinary incontinence in nursing home residents: a cross-national comparison. Age Ageing. 1997;26(Suppl 2):49-54.

14. Irwin DE, Milsom I, Hunskaar S, et al. Population-based survey of urinary incontinence, overactive bladder, and other lower urinary tract symptoms in five countries: results of the EPIC study. Eur Urol. 2006;50(6):1306-15.

15. Suskind AM, Kowalik C, Quanstrom K, et al. The impact of frailty on treatment for overactive bladder in older adults. Neurourol Urodyn. 2019;38(7):1915-23.

16. DuBeau CE, Kraus SR, Griebling TL, et al. Effect of fesoterodine in vulnerable elderly subjects with urgency incontinence: a double-blind, placebo controlled trial. J Urol. 2014; 191(2):395-404.

17. Josephson KL, Ginsberg DA. Key considerations when treating the older patient with symptoms of urinary frequency and urgency. Ann Long-term Care. 2004:12(11). Available from: https://www.managedhealthcareconnect.com/article/3419

18. Kinsey D, Pretorius S, Glover L, Alexader T. The psychological impact of overactive bladder: a systematic review. J Health Psychol. 2016;21(1):69-81.

19. Jayadevappa R, Chhatre S, Newman DK, Schwartz JS, Wein AJ. Association between overactive bladder treatment and falls among older adults. Neurourol Urodyn. 2018;37(8):2688-94.

20. Nakagawa H, Niu K, Hozawa A, et al. Impact of nocturia on bone fracture and mortality in older individuals: a Japanese longitudinal cohort study. J Urol. 2010;184(4):1413-18.

21. Brown JS, Vittinghoff E, Wyman JF, et al. Urinary incontinence: does it increase risk for falls and fractures? J Am Geriatr Soc. 2000;48(7):721-25.

22. Szabo SM, Gooch KL, Walker DR, Johnston KM, Wagg AS. The association between overactive bladder and falls and fractures: a systematic review. Adv Ther. 2018;35(11):1831-41.

23. Shaw C, Cahill J, Wagg A. The current state of continence in Canada: a population representative epidemiological survey. Can J Urol. 2020;27(4):10300-305.

24. Irwin DE, Mungapen L, Milsom I, Kopp Z, Reeves P, Kelleher C. The economic impact of overactive bladder syndrome in six Western countries. BJU Int. 2009;103(2):202-09. 


\section{HEESAKKERS: SAFETY OF FESOTERODINE IN OLDER OAB PATIENTS}

25. Chapple C, Oelke M, Kaplan SA, Scholfield D, Arumi D, Wagg AS. Fesoterodine clinical efficacy and safety for the treatment of overactive bladder in relation to patient profiles: a systematic review. Curr Med Res Opin. 2015;31(6):1201-43.

26. Burkhard FC, Bosch JL, Cruz F, et al. Urinary incontinence [guidelines]. Arnhem, The Netherlands: European Association of Urology; n.d. Available from: https://uroweb.org/guideline/ urinary-incontinence/

27. Malhotra BK, Wood N, Sachse R. Influence of age, gender, and race on pharmacokinetics, pharmacodynamics, and safety of fesoterodine. Int J Clin Pharmacol Ther. 2009;47(9):570-78.

28. Toviaz ${ }^{\circledR}$ (fesoterodine fumarate) [prescribing information]. Sandwich, Kent: Pfizer; 2012. Available from: http://www. medicines.org.uk/emc/medicine/20928

29. Gamé X, Peyronnet B, Cornu JN. Fesoterodine: pharmacological properties and clinical implications. Eur J Pharmacol. 2018;833:155-57.

30. Pratt TS, Suskind AM. Management of overactive bladder in older women. Curr Urol Rep. 2018;19(11):92.

31. Kerdraon J, Robain G, Jeandel C, et al. [Impact on cognitive function of anticholinergic drugs used for the treatment of overactive bladder in the elderly]. Prog Urol. 2014;24(11):672-681. French.

32. Cetinel B, Onal B. Rationale for the use of anticholinergic agents in overactive bladder with regard to central nervous system and cardiovascular system side effects. Korean J Urol. 2013;54(12):806-15.

33. Wagg A, Khullar V, Marschall-Kehrel D, et al. Flexible-dose fesoterodine in elderly adults with overactive bladder: results of the randomized, double-blind, placebo-controlled study of fesoterodine in an aging population trial. J Am Geriatr Soc. 2013;61(2):185-93.

34. Kay GG, Maruff P, Scholfield D, et al. Evaluation of cognitive function in healthy older subjects treated with fesoterodine. Postgrad Med. 2012;124(3):7-15.

35. Abrams $\mathrm{P}$, Andersson KE. Muscarinic receptor antagonists for overactive bladder. BJU Int. 2007;100(5):987-1006.

36. Wagg A, Khullar V, Michel MC, Oelke M, Darekar A, Bitoun CE. Long-term safety, tolerability and efficacy of flexibledose fesoterodine in elderly patients with overactive bladder: open-label extension of the SOFIA trial. Neurourol Urodyn. 2014;33(1):106-14.

37. Wagg A, Darekar A, Arumi D, Khullar V, Oelke M. Factors associated with dose escalation of fesoterodine for treatment of overactive bladder in people $>65$ years of age: a post hoc analysis of data from the SOFIA study. Neurourol Urodyn. 2015;34(5):438-543.

38. Kraus SR, Ruiz-Cerdá JL, Martire D, Wang JT, Wagg AS. Efficacy and tolerability of fesoterodine in older and younger subjects with overactive bladder. Urology. 2010;76(6):1350-57.

39. Chapple C, Van Kerrebroeck P, Tubaro A, et al. Clinical efficacy, safety, and tolerability of once-daily fesoterodine in subjects with overactive bladder. Eur Urol. 2007;52(4):1204-12.

40. Nitti VW, Dmochowski R, Sand PK, et al. Efficacy, safety and tolerability of fesoterodine for overactive bladder syndrome. $J$ Urol. 2007;178(6):2488-94.

41. Sand PK, Heesakkers J, Kraus SR, Carlsson M, Guan Z, Berriman S. Long-term safety, tolerability and efficacy of fesoterodine in subjects with overactive bladder symptoms stratified by age: pooled analysis of two open-label extension studies. Drugs Aging. 2012;29(2):119-31.

42. Chapple CR, Mironska E, Wagg A, et al. Multicriteria decision analysis applied to the clinical use of pharmacotherapy for overactive bladder symptom complex. Eur Urol Focus. 2020;6(3):522-30. Erratum in: Eur Urol Focus. 2021 Jan 6.

43. Saliba D, Elliott M, Rubenstein LZ, et al. The Vulnerable Elders Survey: a tool for identifying vulnerable older people in the community. J Am Geriatr Soc. 2001;49(12):1691-99.

44. Wagg A, Arumi D, Herschorn S, et al. A pooled analysis of the efficacy of fesoterodine for the treatment of overactive bladder, and the relationship between safety, co-morbidity and polypharmacy in patients aged 65 years or older. Age Ageing. 2017;46(4):620-26.

45. Yonguc T, Sefik E, Inci I, et al. Randomized, controlled trial of fesoterodine fumarate for overactive bladder in Parkinson's disease. World J Urol. 2019;38(8):2013-19.

46. Vouri SM, Schootman M, Strope SA, Xian H, Olsen MA. Antimuscarinic use and discontinuation in an older adult population. Arch Gerontol Geriatr. 2019;80:1-11.

47. Qin L, Luo X, Zou KH, Snedecor SJ. Economic impact of using fesoterodine for the treatment of overactive bladder with urge urinary incontinence in a vulnerable elderly population in the United States. J Med Econ. 2016;19(3):229-35.

Correspondence to: John Heesakkers, Department of Urology, Radboud University Medical Center, Geert Grooteplein Zuid 10, Nijmegen 6525 GA, The Netherlands

E-Mail: John.Heesakkers@radboudumc.nl 